\title{
An Audit of Colorectal Cancer Reports in a Sri Lankan Tertiary Care Setting
}

\author{
S A Gunaratne, K Samarasinghe \\ Department of Pathology, Faculty of Medical Sciences, University of Sri Jayawardenepura
}

\begin{abstract}
Introduction: Histopathology reports of colorectal cancer describe essential histopathological factors that influence the treatment and prognosis of colorectal cancer. Incomplete reports can convey misleading information resulting in improper or inadequate management.

Objective: To audit the content of histopathology reports of colorectal cancer in a single tertiary care centre and compare findings with a similar audit done in 2000.

Method: Histopathology reports of 134 patients with colorectal cancer, from January 2002 to October 2006, from the department histopathology of the Sri Jayewardenepura University, were evaluated using the minimum dataset for colorectal cancer reporting required for proper patient management of the Royal College of Pathologists of UK and the College of Pathologists of Sri Lanka. Results were compared with a previous audit done in Sri Lanka (Hewavisenthi et al, 2000).

Results: The majority of data items were mentioned in more than $75 \%$ of the reports in the current and previous (2000) audit. The minimum data items were mentioned more frequently in this audit than in the 2000 study. Three items namely TNM stage, involvement of circumferential margin and relationship of tumour to the peritoneal reflection were poorly mentioned in both audits. Total number of lymph nodes and lymphovascular invasion were mentioned more often in the current audit.

Conclusion: The quality and completeness of histopathology reports has improved with time. Data Items that were mentioned in more than 75\% reports in the 2000 audit were mentioned in more than $90 \%$ in the current audit. However data items such as TNM staging, circumferential margin involvement and relationship to the peritoneal reflection are frequently omitted in both. It is recommended that a proforma containing minimum data variables be used for reporting colorectal cancer to rectify these omissions and the results evaluated.
\end{abstract}

Keywords: colorectal carcinoma, reporting, dataset.

\section{Introduction}

Histopathological evaluation of colorectal cancer (CRC) provides indispensable information for the clinical management of the patient. For the individual patient, it confirms the diagnosis and describes the factors that affect prognosis, mainly the pathological stage and completeness of local excision.

Address for correspondence: S.A. Gunaratne, 90/1 Galle Road, Mount Lavinia, Sri Lanka. e-mail: sandigunaratne@yahoo.com 
Under health care evaluation, pathology reports provide information for cancer registration, clinical audit and assessing the accuracy of new diagnostic and preoperative staging techniques as well as the effect of neoadjuvant therapy. Incomplete histopathology reports convey misleading information and can result in inappropriate therapy. It is, therefore, necessary to audit the quality and completeness of colorectal reports periodically. Guidelines on the information content of pathology reports on colorectal cancer have been published by various expert working groups. ${ }^{1-3}$ The Royal College of Pathologists (RCP) have a minimum data set which is practical, evidence based, frequently updated and widely used. ${ }^{4}$ The College of Pathologists of Sri Lanka have formulated a similar mandatory data set. ${ }^{5}$

We aimed to audit the completeness of histopathology reports of colorectal cancer specimens in our centre according to the minimum dataset of the Royal College of Pathologists of UK and the dataset of the College of Pathologists of Sri Lanka. We also compared our results with an audit done in the year 2000 in Sri Lanka by Hewavisenthi et al on histopathological reports of CRC of 213 cases from the departments of pathology in the Colombo and Gampaha districts. ${ }^{6}$

\section{Material and Methods}

One hundred and thirty four (134) CRC reports from January 2002 to October 2006, from the department of histopathology of the Sri Jayawardenepura University, were evaluated against the minimum dataset for colorectal cancer reporting of the Royal College of Pathologists of UK and the College of Pathologists of Sri Lanka. Results were compared with the audit done in 2000 by Hewavisenthi et al. Only the information content of reports were audited and not the diagnostic precision.

\section{Results}

Out of the 134 reports that were audited, 106 were of rectal cancers. The rest of the cancers were from other parts of the colon. Eleven items were mentioned in more than $90 \%$ of the reports (Table 1). Six items namely, TNM stage, neural invasion, obstruction, perforation and in rectal tumours circumferential resection margin and the relationship to the peritoneal reflection were reported in less than $25 \%$ of the reports. Table 1 contains the summary of the se results. The mean number of lymph nodes isolated per case was 9.

In the audit done in 2000, 213 cases were audited of which 76 were rectal cancers.

Table 2 shows the details of the audit and comparison of our data to the audit done in $2000 .^{6}$ The majority of data items were mentioned in more than $75 \%$ reports in both studies (figure 1). In our study they were mentioned more frequently than in the year 2000 study. TNM stage, involvement of circumferential margin and relationship of tumour to the peritoneal reflection were poorly mentioned in both studies (figure 2). Total number of lymph nodes and lymphovascular invasion were mentioned far more frequently than in 2000. 
Table 1. Percentages of mention of data items in reports.

\begin{tabular}{|c|c|c|}
\hline $\begin{array}{l}\text { Items mentioned in } \\
>90 \% \text { of reports }\end{array}$ & $\begin{array}{l}\text { Items mentioned in } \\
<25 \% \text { of reports }\end{array}$ & $\begin{array}{l}\text { Items mentioned in around } \\
50 \% \text { of reports }\end{array}$ \\
\hline $\begin{array}{l}\text { Site } \\
\text { Distance from tumour to resection } \\
\text { margin } \\
\text { Diameter of the tumour } \\
\text { Histological diagnosis } \\
\text { Degree of differentiation } \\
\text { Dukes stage } \\
\text { Total no of lymph nodes isolated } \\
\text { Number of nodes with metastasis } \\
\text { Lymphatic and venous invasion } \\
\text { Adequacy of resection } \\
\text { Depth of invasion }\end{array}$ & $\begin{array}{l}\text { Neural invasion } \\
\text { Obstruction } \\
\text { Perforation } \\
\text { TNM stage } \\
\text { Metastasis in apical } \\
\text { node } \\
\text { Circumferential margin* } \\
\text { Relationship to } \\
\text { peritoneal reflection* }\end{array}$ & Background abnormalities \\
\hline
\end{tabular}

$*$ in rectal tumours only

Table 2. Audited data items in comparison to the audit done in 2000 by Hewavisenthi et al. ${ }^{6}$

\begin{tabular}{|l|l|l|l|l|}
\hline \multirow{2}{*}{ Item } & \multicolumn{2}{|c|}{2006} & \multicolumn{2}{c|}{2000} \\
\cline { 2 - 5 } & Number & $\%$ & Number & $\%$ \\
\hline Site of the tumour & 134 & $100 \%$ & 213 & $100 \%$ \\
\hline Diameter of the tumour & 126 & $94 \%$ & - & - \\
\hline Distance of tumour to resection margin & 120 & $89.6 \%$ & 163 & $76.9 \%$ \\
\hline Histological type & 134 & $100 \%$ & - & $99.1 \%$ \\
\hline Degree of differentiation & 134 & $100 \%$ & 211 & $94.9 \%$ \\
\hline Background pathological abnormalities & 55 & $41 \%$ & - & - \\
\hline Dukes staging & 129 & $96.2 \%$ & 174 & $81.7 \%$ \\
\hline TNM staging & 21 & $15.7 \%$ & 11 & $0.05 \%$ \\
\hline Total number of lymph nodes isolated & 120 & $89.6 \%$ & 56 & $26.3 \%$ \\
\hline Apical lymph node metastasis & 16 & $11.9 \%$ & - & - \\
\hline $\begin{array}{l}\text { Presence / absence of } \\
\text { of lymph node metastasis }\end{array}$ & 129 & $96.7 \%$ & 153 & $71.8 \%$ \\
\hline Depth of invasion & & & & \\
\hline Neural invasion within tumour & 133 & $99.2 \%$ & 211 & $99.1 \%$ \\
\hline Vascular or lymphatic invasion within tumour & 24 & $17.9 \%$ & - & - \\
\hline Resection margin(doughnut) & 134 & $100 \%$ & 32 & $15 \%$ \\
\hline Presence/absence of perforation & 122 & $91 \%$ & 198 & $93 \%$ \\
\hline Presence/ absence of obstruction & 17 & $12.8 \%$ & - & - \\
\hline Rectal specimens & 10 & $7.5 \%$ & - & - \\
\hline Involvement of circumferential margin & & & & \\
\hline $\begin{array}{l}\text { Relationship of tumour to peritoneal } \\
\text { reflection }\end{array}$ & 29 & $27.6 \%$ & 5 & $6.6 \%$ \\
\hline & 23 & $21.2 \%$ & 0 & $0 \%$ \\
\hline
\end{tabular}


Figure 1.

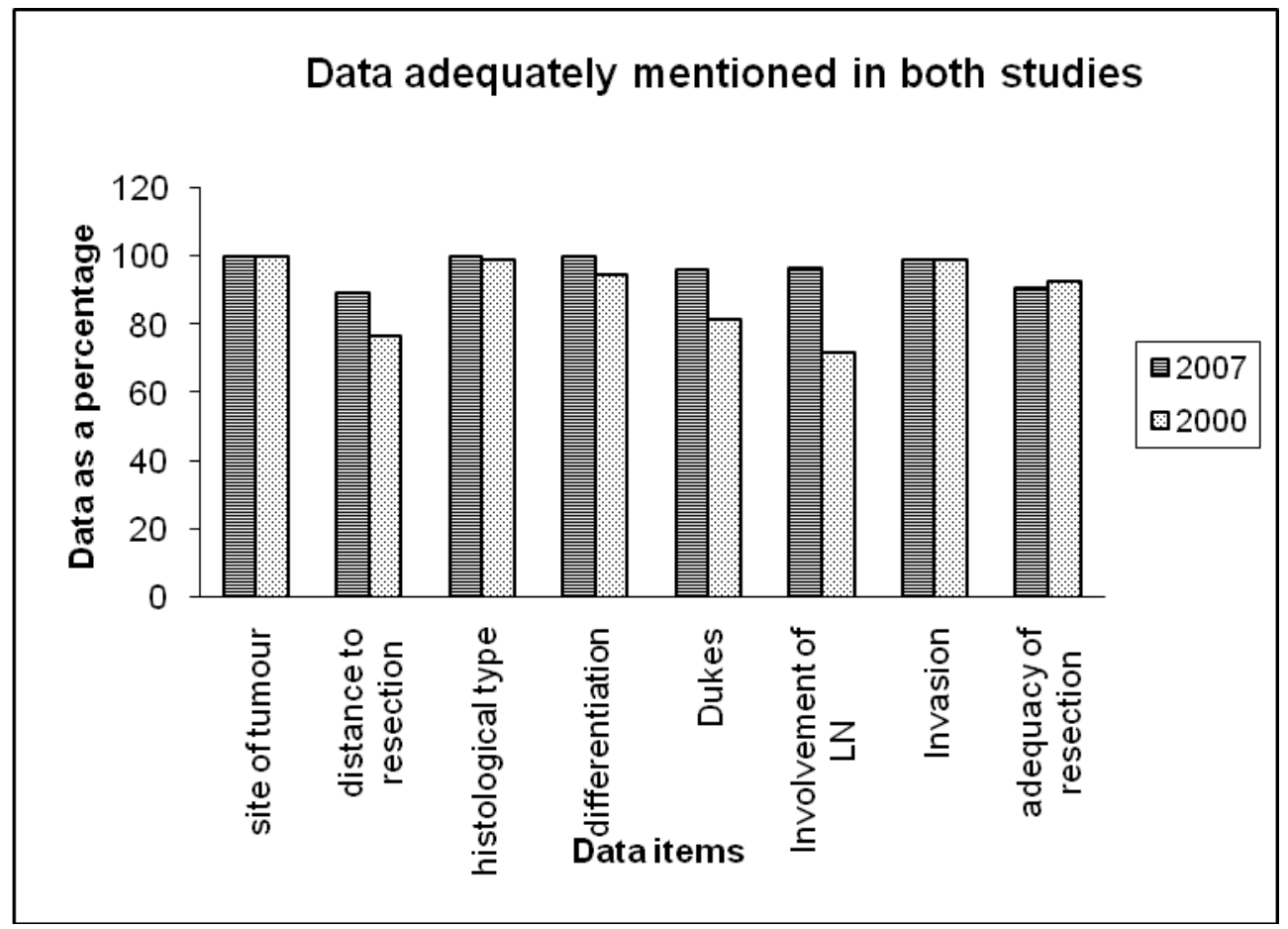

Figure 2.

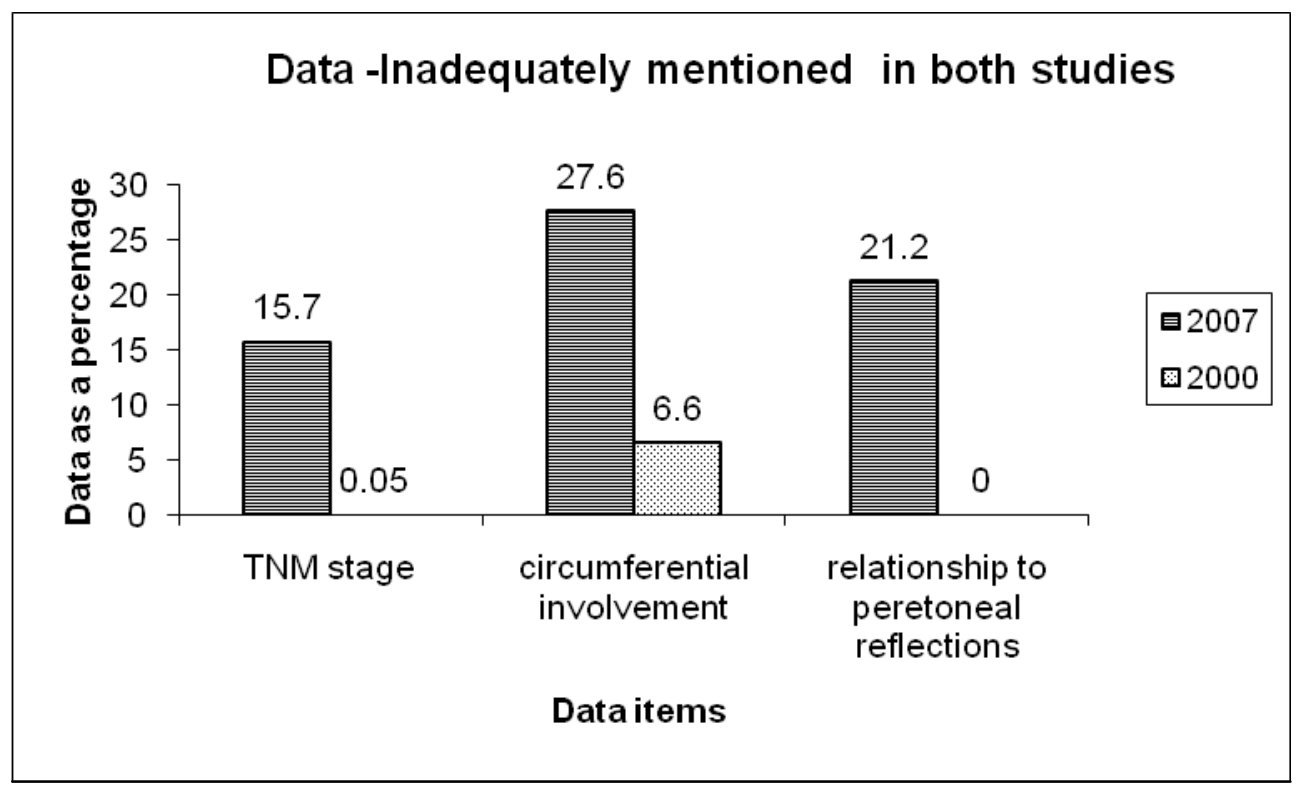


Figure 3.

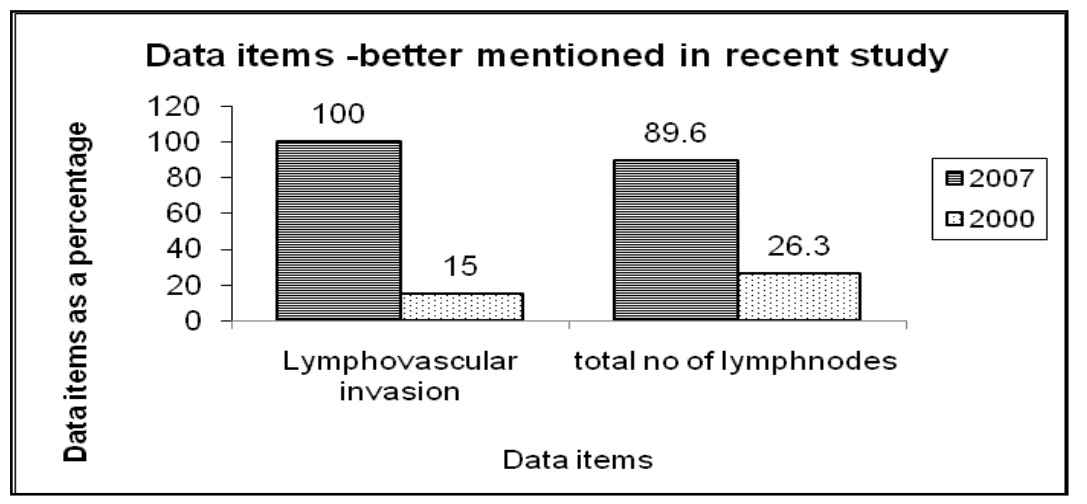

\section{Discussion and conclusion}

The histological diagnosis and the degree of differentiation was given in all reports in the 2007 study and included in more than $90 \%$ of reports in 2000 . The degree of differentiation and the histological type of cancer are recognized histological prognostic factors for colorectal cancer. It is known that non mucinous carcinoma and mucinous carcinoma differ in their 5-year survival rates $(62 \%$ vs. $53 \%){ }^{2}$

In both studies Dukes stage was mentioned in a great majority of the reports but TNM staging was poorly recorded. Dukes staging links two factors, depth of local penetration and lymph node metastasis; these are related but to some extent are independent and therefore both the staging systems must be included, although TNM staging for carcinoma of colon and rectum provide more details than the Dukes staging system. Compared to the Dukes stage, greater precision in identification of prognostic subgroups is seen in TNM staging and there is better inter-observer correlation.

The presence or absence of node involvement was well mentioned in 2000 and in our study but there was a marked improvement in mentioning the total number of nodes in our audit (89.60\% vs. $26.30 \%$ ). Apical node involvement was mentioned only in $11.9 \%$ of the reports in our study. This variable was not considered in the previous study. The influence of lymph node metastasis on prognosis is well known, and the relationship applies to the total number isolated, number of nodes involved and the site of the node.

In the present study the overall mean value for lymph node isolation was approximately nine (09) lymph nodes per specimen. The American Joint Committee on Cancer recommends that at least 12 lymph nodes should be examined in patients with colon and rectal cancer to confirm the absence of nodal involvement ${ }^{8}$ while others recommend that 14-15 nodes should be isolated $^{1}$. In a study done in the United Kingdom 9 nodes were isolated per specimen in 1996 and 12 in the year 2000. ${ }^{9} \quad$ In a French study the mean value was 11 nodes per case. ${ }^{10}$ It is apparent that this variable seems to be poorly reported in other parts of the world as well. The use of Carnoy's fixative to dissolve fat may have resulted in a higher yield of lymph nodes in other countries.

Venous invasion and perineural invasion are important predictive factors of hepatic metastasis and survival. ${ }^{1,3}$ A significant improvement from $15 \%$ to $100 \%$ was seen in documentation of 
lymphovascular invasion when comparing the two audits. Nerve involvement was mentioned in $17.9 \%$ cases in our study.

Intestinal obstruction is the most common complication of carcinoma of the large bowel, which is associated with relatively advanced disease. ${ }^{1,3}$ Free perforation is uncommon and indicates an unfavorable prognosis due to peritonitis and dissemination of malignant cells into the abdominal cavity. Perforated tumours are regarded as pT4 irrespective of other factors ${ }^{4}$ so aggressive treatment is recommended. Results pertaining to obstruction and perforation must be interpreted with caution since it is considered absent if not mentioned in the report. This may be the cause of a low rate of inclusion of these factors in this study.

The most important deficiency noted in both studies was the poor description of circumferential resection margin involvement in rectal carcinoma which is less than $30 \%$. This incomplete pathological reporting may compromise effective treatment. ${ }^{12,13}$ Involvement of the circumferential resection margin in rectal cancer is an important prognostic indicator. It has a high predictive value for both survival and recurrence. ${ }^{1,11}$ The frequency of circumferential margin involvement found may indicate the quality of rectal surgery being performed. ${ }^{11}$

The frequent failure of reports to contain this information was also seen in audits done in France and United Kingdom. ${ }^{10,13}$ In the United Kingdom study it was mentioned in $57.6 \%$ of reports and in France in $61 \%$ of the reports. This factor needs urgent remedial measures.

In the local audit of year 2000 none of the reports had mentioned the relationship of tumour to the peritoneal reflection and in ours only $21.20 \%$ of reports had this information. Tumours below the peritoneal reflection have the highest rate of local recurrence, therefore it is vital that this information is given in reports. ${ }^{4,14}$ In the study done by Beattie et al in 1996, it was found that only $1 \%$ had mentioned this factor but in the 2000 Sri Lankan audit, it was reported $75 \%$ of the reports after introducing a proforma. ${ }^{9}$

From our study we can conclude that the quality and completeness of histopathology reports have improved with time. The information that was mentioned more than $75 \%$ of the reports in the previous Sri Lankan audit in the year 2000 was mentioned in more than $90 \%$ of our reports. However of the items that were mentioned inadequately in their study namely TNM staging, circumferential margin involvement and relationship to the peritoneal reflection were frequently omitted in both audits. In addition, the status of the apical node was also poorly reported. However there is a marked improvement seen over the years in mentioning the total number of lymph nodes, vascular and lymphatic invasion.

\section{Recommendations}

- It has been found in some studies that when a proforma was used in the reporting, the inclusion rates nearly approached $100 \%$ in all categories ${ }^{13-15}$ and it was quicker to use the proforma than to dictate a report. Therefore it is recommended that a proforma be used here as well.

- Pathologists' interaction with clinicians is of paramount importance in preventing and detecting errors and omissions in reporting. Therefore regular clinicopatholgical meetings should be held. 
- Clinician friendly pathology reports should clearly mention the most important data in the summary or it should be written in bold.

\section{References}

1. Rosai J. Ackerman's Surgical Pathology Vol. $1.9^{\text {th }}$ ed. St. Louis: Mosby; 2004. 336-40.

2. Day DW, Jass JR, Price AB, Shepard N, Sloan JM. Morson \& Dawson's Gastrointestinal Pathology. $4^{\text {th }}$ ed. Massachusettes: Blackwell Science; 2003. 584-7.

3. Vincent I, De Vita JR, Hellmann S, Rosenberg A. Principles and Practice of Oncology. $6^{\text {th }}$ ed. Lippincott, Williams and Wilkins; 2001.

4. The Royal College of Pathologists. Standards and minimum datasets for reporting common cancers: Minimum dataset for colon cancer histopathology reports. London: Royal College of Pathologists; 2000.

5. Hewavisenthi J, Fernando R, Illeperuma A, Beneragama D, Jayaweera G et al. Reporting of common gastrointestinal malignancies. Colombo: Ministry of Healthcare and Nutrition; 2007. 83-96.

6. Hewavisenthi SJ De S, Samarasekera DS, Priyadarshani JWS. Colorectal carcinoma: an audit of histopathology reports. Journal of Diagnostic Pathology. 2000; 1: 19-22.

7. Blenkinsopp WK, Stewart-Brown S, Blesovosksy I et al. Histopathology reporting in large bowel cancer. Journal of Clinical Pathology. 1981; 34: 509-13.

8. Website of the National Cancer Institute of Sri Lanka. Available from: URL: http://www/cancer.com

9. Beattie GC, McAdams TK, Elliot S et al. Improvement in quality of colorectal cancer pathology reporting with standardized proforma - a comparative study. Colorectal Disease. 2002; 5: 558-61.

10. Eon Y, Le Douy J, Lamer B et al. Quality and completeness of histopathology reports of rectal cancer resections - results of an audit in Brittany. Gastroenterologie Clinique. 2006; 30(2): 235-40.

11. Ng OL, Luk ISC, Yuen ST et al. Surgical lateral clearance in resected rectal carcinomas: A multivariate analysis of clinicopathogic features. Cancer. 1993; 71: 1972-6.

12. Abulafi AM, Williams NS. Local recurrence of colorectal cancer: the problem, mechanisms, management and adjuvant therapy. British Journal of Surgery. 1994; 81: 07-19.

13. Bull AD, Biffin AH, Mella J et al. Colorectal cancer pathology reporting: a regional audit. Journal of Clinical Pathology. 1997; 50: 138-42.

14. Quirk P, Morris E. Reporting of colorectal cancer. Histopathology. 2007; 50: 103-12.

15. Cross S, Feely KM, Carole AA. The effect of four interventions on the informational content of histopathology reports for resected colorectal carcinomas. Journal of Clinical Pathology. 1998; 51: 481-2. 